\title{
A MODEL OF ASEAN COLLABORATION IN TOURISM
}

by Emma P.Y. Wong, Nina Mistilis, Larry Dwyer

University of New South Wales, Australia

\begin{abstract}
Intergovernmental collaboration in tourism among ASEAN nations has received little attention in the literature despite the significant contribution that tourism makes to the region. In this paper, the authors propose a model that displays the mechanism of ASEAN tourism collaboration. The model emphasizes the environments in which collaboration takes place. It also highlights the interactivity of various components: among actors, between the institutional arrangement and the actors, and the feedback mechanisms between the collaborative process and the preconditions of collaboration. The model captures the unique features of this collaboration and helps to expand the boundaries of existing theories and thus contribute to our knowledge of the key drivers of successful tourism collaboration among nations.
\end{abstract}

KEYWORDS: Intergovernmental collaboration; ASEAN tourism

\section{INTRODUCTION}

Despite the continuous endeavor among the Association of Southeast Asian Nations (ASEAN) member nations to develop cooperation on tourism, and the significant economic contribution that tourism makes to these countries, there are very few studies that examine ASEAN tourism collaboration. The majority of existing studies that are related to ASEAN economic cooperation deal with general framework agreements, namely ASEAN Free Trade Agreement (AFTA) and ASEAN Framework Agreement on Services (AFAS). Collaboration in specific economic sectors is largely overlooked by researchers.

ASEAN was established as a means to maintain peace and stability in Southeast Asia by providing a forum for the discussion and resolution of regional issues which had the potential to destabilize the region. Five countries officially formed the Association on 8 August 1967: Indonesia, Malaysia, the Philippines, Singapore and Thailand. Together with Brunei, which joined on 8 January 1984, the six countries are also known as ASEAN-6.

With the fall of Communism in Eastern Europe and the end of the Cold War, there was no longer a pressing need for ASEAN countries to fear their Communist neighbors such as Vietnam, Cambodia and Laos. These countries had started to abandon central planning and implement market-oriented economic reforms from the early 1980s, changes which had significant implications for trade and investment opportunities and indicated the need for enlargement of the ASEAN regional grouping in order to maintain its relevance. 
The momentum to expand ASEAN was further accelerated by the need to strengthen the region's voice in international trading bodies such as the Asia-Pacific Economic Cooperation (APEC) forum, the World Trade Organization, and in negotiations with the European Union (Tan, 2003). Between 1995 and 1997, Cambodia, Laos, Myanmar and Vietnam (CLMV) joined ASEAN. They are sometimes referred to as newer members with less-developed economies.

The long-term goal of ASEAN is to establish a free trade area in Southeast Asia (Yeh, 2002). While ASEAN's economic emphasis has most often focused on trade in manufactured goods, minerals and fuels, tourism has grown to become an important consideration, in large part due to the rapid growth of the industry in the region (Timothy, 2003). In 2008, the region received 65.5 million tourists, almost double the figure of 33 million visitor arrivals just six years earlier in 2002 (UNWTO, 2003; ASEAN, 2009a). From a level of 81 million in 1995, international visitor arrivals are forecast to increase to 397 million by 2020 , representing an annual average growth rate of $6.5 \%$ for the period 1995-2020, almost 2.5 percentage points above the global growth rate of $4.1 \%$ (UNWTO, 2003). Intra-regional travel comprises a relatively high proportion of travel within Asia. By 2020, regional arrivals are projected to reach 136 million per annum (UNWTO, 2000) - illustrating the growing importance of tourism for, and the level of interdependence among ASEAN nations.

Table 1 shows the contribution of travel and tourism to individual ASEAN members' gross domestic product (GDP). Across the region in 2009, tourism accounted for $11 \%$ of ASEAN's GDP. It is fair to say that tourism makes a significant contribution to ASEAN economies.

(Insert Table 1 here)

\section{BACKGROUND OF ASEAN TOURISM COLLABORATION}

ASEAN was first established to maintain peace and stability in Southeast Asia. Member countries were not drawn to cooperate economically until the 1990s when they moved to protect the region against threats of protectionism from the European and North American free-trade blocs. Later in the decade, the devastation caused by the Asian Financial Crisis served as a wake up call to national leaders about the importance of cohesion to the region's economic stability and prosperity. From then on, a number of landmark strategic plans and agreements were launched with the long-term goal of establishing a free trade area or a common market in Southeast Asia (Tan, 2003), starting with the ASEAN Vision 2020 in 1997, followed by the Hanoi Plan of Action (HPA) in 1998, the Initiative for ASEAN 
Integration (IAI) in 2002, and the Bali Concord II in 2003.

Tourism, a trade activity common to all member countries, was identified as one of the specific areas of cooperation within the ASEAN general economic cooperation framework. In the beginning, when a permanent committee of tourism was formed in 1969, tourism collaboration was there to support the wider economic cooperation project. Until the Asian Financial Crisis in the late 1990s, cooperative efforts such as the ASEAN Tourism Forum (ATF) that started in 1981, the establishment of the Tourism Information Centre in 1988 (closed down in 1996), and the Visit ASEAN Campaign (VAC) that started in 1991 were relatively insignificant and unstructured.

While Southeast Asia was still recovering from the Asian Financial Crisis, the tourism industry in the region and around the world was threatened by the terrorist attack in the US on 11 September 2001. As a measure to strengthen the unity amongst members, to enhance competitiveness, and to increase tourist flows, the ASEAN Tourism Agreement was conceived at the ASEAN Summit in November 2001 (ASEAN, 2002).

The Agreement contains seven objectives (ASEAN, 2002):

(1) To cooperate in facilitating travel into and within ASEAN.

(2) To enhance cooperation in the tourism industry among ASEAN member states in order to improve its efficiency and competitiveness.

(3) To substantially reduce restrictions to trade in tourism and travel services among ASEAN member states.

(4) To establish an integrated network of tourism and travel services in order to maximize the complementary nature of the region's tourist attractions.

(5) To enhance the development and promotion of ASEAN as a single tourism destination with world-class standards, facilities and attractions.

(6) To enhance mutual assistance in human resource development and strengthen cooperation to develop, upgrade and expand tourism and travel facilities and services in ASEAN.

(7) To create favorable conditions for the public and private sectors to engage more deeply in tourism development, intra-ASEAN travel and investment in tourism services and facilities.

In 2004, the Roadmap for Integration of the Tourism Sector was introduced by the ASEAN Economic Ministers (AEM) to serve as an action plan for implementing the seven agreement objectives. The integration exercise across various economic sectors is envisaged to be completed by 2015 in an attempt to establish the ASEAN Economic Community (ASEAN, 2006). 
In the academic literature, there are few studies that have examined in-depth the intergovernmental collaboration phenomenon in ASEAN tourism. However, two recently published articles inform the present study. Wong et al. (2010) examining the preconditions of ASEAN tourism collaboration and the formulation of its policy framework, concluded that the formation of collaboration in tourism was directly driven by the requirements set out by the broader ASEAN cooperation framework (see for example ASEAN Framework Agreement on Services). Under the framework, tourism was one of the chosen sectors for regional economic collaboration. There are also indirect drivers, namely reciprocity and stability. That is to say, the ASEAN members want to pursue common interests in promoting the region to the long haul market, and to achieve stability, predictability and dependability through such collaboration. The article also highlighted the pragmatic approach to ASEAN policy-making, and that changes in the larger economic and political environment (e.g. the 9/11 terrorist attack in the US, Bali bombing in 2002, and their effects) have elevated the common interests among members resulting in more cohesive relationships.

In a second article, Wong et al. (2011) evaluated the progress in collaboration since the inception of the ASEAN Tourism Agreement in 2002 and the corresponding action plan 'Roadmap for Integration of the Tourism Sector' in 2004. The paper also identified factors that facilitated and hindered progress in respect of successful collaboration and categorized them along three dimensions - stakeholders, resources, and processes and mechanisms. It was argued that although relatively significant progress was made in travel facilitation and human resources development, many of the measures suggested in the action plan were either not implemented at all or delayed.

The proposed model in this paper was constructed firstly by drawing on the existing literature in international relations and interorganizational relations. There appears to be no model in the literature that describes or analyzes mechanisms of intergovernmental collaboration in a comprehensive manner. Therefore, a range of studies was consulted for the different components of the proposed model. For example, Oliver's (1990) generalizable determinants of relationship formation inform the preconditions component of the model, and Young's (1982) theories on regime transformation inform the macro-environment component. These theories formed the basis of the proposed model. Second, the draft model was modified and tailored to the ASEAN context by integrating triangulated empirical data.

This paper makes its theoretical contribution by identifying the congruence and discrepancies between theories and empirical findings. There are certain aspects of ASEAN tourism collaboration which existing theories do not fully explain. As Yin (2003:32) points 
out, a case study can make a theoretical contribution by means of "analytical generalization", whereby the contextual boundaries of theories are extended with new empirical evidence. It is in this way that this case study of ASEAN tourism collaboration makes its theoretical contribution.

Each supranational organization forms and operates in a specific context. Often, existing theories cannot fully explain the various interactions within these organizations or their relative influence on outcomes. In this paper, the authors propose a model that provides a graphical representation of the mechanism of ASEAN tourism collaboration. The role of the model is to explain the ASEAN tourism collaboration phenomenon. Its value is beyond descriptive as it not only describes what happened or who were involved, but also analyzes and explains why the collaboration takes place, and what facilitates the process. It captures the unique features of this collaboration and helps expand the boundaries of existing theories and thus contributes to the literature. It is also a useful lens for examining the collaboration phenomenon.

The model emphasizes the environments in which collaboration takes place - the economic and political environment of the world and of the region, as well as the arena of collaboration. It employs concepts that have been formulated in the general management, organizational theory and public policy literature, and highlights the interactivity of various components: among actors, between the institutional arrangement and the actors, and the feedback mechanisms between the collaborative process and the preconditions of collaboration. The interactivities are manifestations of the dynamic nature of collaboration. Due to the fact that the model focuses on the environmental forces and historical factors (e.g. preconditions) that drive ASEAN tourism and the overall mechanism of the collaboration, it will remain relevant unless drastic changes are made to the nature and structure of the collaboration.

\section{METHOD}

Case study was chosen as the research strategy for the investigation. It is deemed appropriate in examining contemporary events when the relevant behaviors cannot be manipulated. The case study approach deals with evidence collected from direct observation of events and interviews of people involved (Yin, 2003).

Following a survey of the literature, the authors collected empirical data and examined how the data confirm or refute the theories behind the model. The respective components were modified accordingly. Various sources of evidence were used in this study, including official documents from ASEAN, non-official publications (e.g. academic journals, books, newspapers and trade magazines), and interviews with key stakeholders involved. The use 
of multiple sources allowed data triangulation and thus enhanced the credibility and dependability of findings (Lincoln and Guba, 1985). The use of both theories and triangulated empirical data in the construction of the model gives it high explanatory power in explaining the ASEAN tourism phenomenon.

In-depth interviews were conducted in January to March 2005 and January to February 2006. Those times were chosen as they coincided with the ASEAN Tourism Forum (ATF) held in January each year. The Forum is a major annual event where heads of national tourism organizations (NTOs), tourism ministers, and industry leaders come together for regional policy level meetings. It provides a facilitating atmosphere for data collection as collaborative issues receive most attention from the public and are openly discussed then.

Individuals who participated in this study can be categorized into four groups: government officials, international organizations (e.g. ASEAN Secretariat; Asian Development Bank), industry associations (e.g. ASEAN Tourism Association; Pacific Asia Travel Association), and academia or consultancies (e.g. Institute of Southeast Asia Studies; Sustainable Tourism Cooperative Research Centre). Respondents were chosen based on the criterion that they have been involved in ASEAN tourism to a considerable degree playing a participatory, leading or coordinating role. If they are academics or consultants, they must be highly knowledgeable about ASEAN.

A total of twenty-two face-to-face and telephone interviews were administered and two email responses received. Twenty-one individuals took part in the study, three of whom were interviewed twice. Among the twenty-one participants, thirteen were high-level government officials, representing nine out of the ten ASEAN member countries. The other eight were from international organizations, industry associations, and academia or consultancies. The number of respondents from governments was predetermined by the limited number of organizations involved in ASEAN tourism. There are two levels of cooperation: NTO- and minister-level. However, NTOs are highly dependent on their respective ministries and have little decision-making power with the exception of Singapore and Thailand. In those cases, there was only one government body per country where data could be collected.

Since respondents were carefully chosen based on the key informant criterion, and that nine out of the ten member countries were represented in the study, the degree of non-response bias is low. The authors, however, acknowledge that there may be individuals who may be qualified to participate in this study but did not take part.

All data were inputted into the software NVivo 2.0 for analysis. NVivo is a data 
management and analytical tool which not only facilitates coding of data, but its searching and modeling tools also enable researchers to confirm propositions and to explore new relationships embedded in the data. The basic underlying logic is that ideas expressed in the data are broken down into simple "units" of concepts and the software can illustrate the relationships among selected concepts in tabular or graphical formats.

Analysis of this study started with "transcripts cleaning", where all transcripts were checked for accuracy by going back to the original audio recording. All entries were then coded based on a set of "tree nodes". Coding is "the process of identifying and recording one or more discrete passages of text or other data items that, in some sense, exemplify the same theoretical or descriptive data" (Gibbs, 2002:57). "Tree nodes" are so called because ideas or concepts are linked together like branches in a tree, with broad concepts branching out to specific ideas which, in some cases, are further broken down. It provides flexibility to the authors to add in new codes during the process of data analysis.

A tree node structure can be considered a conceptual schema. The building of such schema can be concept-driven and/or data-driven. Towards the end of the data collection process, the authors drafted a rough tree node structure based on the literature, the research objectives and the interview questions, i.e. concept-driven. After data analysis commenced, the drafted tree node structure started to change. The building of the conceptual schema then became data-driven. Nodes were modified or deleted if the data suggested that they were no longer applicable. The tree node structure was modified at intervals along the process of data analysis.

This analytical approach allowed the authors to confirm theoretical propositions and explore relationships among data. It provided constructive inputs into the formulation of the model proposed below.

\section{THE ASEAN COLLABORATION MODEL}

The proposed model (Figure 1) has eight components: 1) world economy and politics, 2) regional economy and politics, 3) actors and their interrelationships, 4) preconditions of collaboration, 5) arena of collaboration, 6) the collaborative process, 7) factors that facilitate the collaboration, and 8) feedback mechanisms.

Components 1 to 4 can be considered the wider, macro-environment in which ASEAN collaboration takes place. Component 5, the arena of collaboration, is the micro-environment for ASEAN tourism collaboration. Components 6 to 8 are parts of the process of the collaboration. The model highlights those factors that play a crucial role in determining the success or otherwise of intergovernmental collaboration on any issue. In 
respect of tourism collaboration, it provides a framework for understanding the facilitators and barriers to achieving the seven objectives of the ASEAN Tourism Agreement. To better appreciate this, we need to discuss each of its component parts in turn.

(Insert Figure 1 here)

\section{The macro-environment (Component 1 to 4)}

The world and regional economy and politics are the first two components of the model. They are the contextual environment in which a regime exists, and the sources of exogenous forces (Young, 1982). In the context of tourism, global trends are influencing tourism demand and, on the supply side, have substantial implications for tourism management at both the destination and operator levels. The remote environment of an organization comprises those factors over which it has very little or no control. These factors are often characterized as Political, Economic, Social and Technological (PEST) (Fahey and Narayanan, 1986). Given the importance of the natural Environment, the acronym PEEST or STEEP is often now employed (Evans et al. 2003; Dwyer and Edwards, 2009).

PEEST factors are useful for identifying and structuring some of the more important drivers of change and trends affecting tomorrow's tourism and travel. All such trends comprise the external environment in which consumers make travel related decisions, such as relating to choice of destination, mode of transport, activities and spending; this is the strategic context within which long term tourism industry policies, planning and development are made.

These key drivers of change have been discussed in some detail elsewhere (Hammond, 1998; NIC, 2004; Cetron 2001; Nordin, 2005; Goldblatt et al., 2006; Dwyer et al., 2009). The social environment, the economic, political, and legislative requirements, competition (both domestic and global), and technology continue to advance at a rapid pace. Organizations evolve each day through changes in human resources, knowledge, customer base, and stockholder value but it is imperative that they evolve at the same pace as the external environment. In other words, exogenous forces may lead to alterations in human behavior that undermine the essential elements of a regime. Therefore, one must recognize the significance of exogenous forces and take into account the broader social setting when analyzing a regime (Young, 1982).

The findings confirm the significant influence of the external environment on ASEAN tourism collaboration. The impacts of the 9/11 incident and 2002 Bali bombing are good examples, whereby global tourism and the confidence of tourists were shattered by 
terrorism. The struggling tourism industry received national level attention within ASEAN, and the ASEAN Tourism Agreement was introduced in 2002 to strengthen cohesion in the region. In terms of the impact of the regional environment, the best piece of evidence is the extent to which ASEAN tourism is controlled by the general economic cooperation framework. That is, from establishing the institutional arrangement to formulating the policy agenda, numerous aspects of ASEAN tourism are determined on the economic ministry level. As a result, tourism must compete with other ASEAN economic sectors and political agendas for resources and attention.

Component 3 in the model refers to actors and their interrelationships in collaboration. A group of interrelated actors form a collaborative relationship. From the policy network theory perspective, the political actors who "engage in resource exchange over public policy as a consequence of their resource interdependencies" form a policy network (Compston, 2009:17). These actors in the policy network can be sub-national or national level government bodies (Peters and Pierre, 2001). A set of factors including national interests, domestic politics, and leaders' political interests, may influence the way in which an actor interacts with the others and with the regime (Hall, 2005).

The literature suggests that interrelationships amongst actors are, in turn, characterized by trust, conflict, cohesion, and communication. Dougherty and Pfaltzgraff (1996) assert that the extent to which each party believes that the others will cooperate, and the extent to which mutual rewards arise from cooperation determine the strength of a cooperative relationship. Frequent, transparent communications between states in the forms of negotiation, bargaining, persuasion and information exchanges about the objects of cooperation and the development of institutions are also important determinants of the interrelationships amongst actors (Drysdale, 1988).

In the case of ASEAN tourism, at different stages of collaboration, different actors are involved. For example, formulating the ASEAN Tourism Agreement was a national level decision for each signatory. Thus, the key actors involved in this stage were nation states. Then, the development of the action plan, "Roadmap for Integration", mainly involved economic ministries of member countries. Finally, in the stage of implementation, tourism ministries along with other ASEAN committees such as the Coordinating Committee on Services (CCS) and the Coordinating Committee on Investment (CCI) (Wong et al., 2010) play the key role.

From a political analysis point of view, nation states, economic ministries, and tourism ministries are different as actors because the degree of control over resources, the degree of 
influence they have internationally and domestically, as well as their commitment towards regional cooperation vary. For instance, one of the key messages from the study respondents is the importance of political will and support from their national leaders to the success of tourism collaboration. This is because tourism ministries or national tourism organizations often have little independent power when it comes to direction setting or pushing forward a policy initiative.

"We are doing this strategy, because the Prime Ministers decided in the summit that tourism should be one of the areas for regional cooperation. So that is where the commitment comes. At a very high level, the commitment is already there. The Prime Ministers decide yes, this is important." (International organization representative)

Such observation supports the theories of multilayered supranational governance. Hence, in the model, there is a distinction between different types of state actors. Lobbyists, expert-consultants, or secretariat do not appear to play a crucial role, but the latter two take part as advisers and coordinators respectively.

In terms of the interrelationship amongst actors, the data confirm the relevance of the four main factors identified from the literature: trust, conflict, cohesion, and communication (Hall, 1995; Dougherty and Pfaltzgraff, 1996; Drysdale, 1988). Some interviewees emphasized that the trust built among tourism policy-makers over years of working together is an important facilitating factor.

"Once the trust has been established, once it has been demonstrated that people can work together, and one or two or three projects have worked, let's look in a more comprehensive way." (International organization representative)

Through regular meetings, friendship is developed among them. The sense of mutual understanding allows them to work closer together. Some researchers identify the amity as part of the "ASEAN Way", which is a set of norms unique to ASEAN collaboration (Acharya, 2000).

“... now [contact among] the tourism officials is quite close. People sometimes talk, not only on a formal basis during a meeting, but outside the meeting also they talk to each other ... atmosphere has created, has contributed to the achievement of the objective of each meeting, because ... officials from one country to another could easily understand on the mission being carried by each country in pursuing the cooperation ..." (International organization representative)

“The ASEAN tourism meeting is also not only a meeting ... but also a 
meeting of friends to strengthen the collaboration through friendship. This will become a tool to strengthen aside from the result, the progress ... through this it opens other ... makes it easier for other ... we know each other then it's a lot easier. "(Indonesia government official)

Component 4 relates to the preconditions of ASEAN tourism. Oliver (1990) suggests that there are six generalizable determinants of relationship formation - necessity, asymmetry, reciprocity, efficiency, stability, and legitimacy. The determinants are not mutually exclusive and may coexist. Necessity refers to a relationship formed to meet necessary legal or regulatory requirements; asymmetry for relationships prompted by the potential to exercise power or control over another organization or its resources; reciprocity when organizations want to pursue common or mutually beneficial goals or interests; efficiency when organizations want to improve their internal output/input ratio; stability when environmental uncertainty prompts organizations to establish relationship to achieve stability, predictability, and dependability in their relations with others; and finally, legitimacy for relationships that are established to demonstrate or improve an organization's reputation or congruence with prevailing norms in its institutional environment.

As Wong et al. (2010) suggest, the formation of collaboration in tourism among ASEAN nations was directly driven by necessity, i.e. the requirements set out by the broader ASEAN cooperation framework (e.g. the ASEAN Framework Agreement on Services). The indirect drivers to the relationship were reciprocity and stability. That is, the ASEAN members want to pursue common interests in promoting the region to the long haul market, and to achieve stability, predictability and dependability through the collaboration. However, Wong et al. note that the tourism industry is competitive in nature and ASEAN countries do compete against each other for tourism dollars. For example, Bali in Indonesia, Langkawi in Malaysia and Phuket in Thailand are famous 'sun and beach' destinations that attract similar tourist market segments. Competition is, therefore, inevitable. The rationale behind ASEAN tourism collaboration was mainly supporting the wider economic agenda of ASEAN. Out of the six preconditions in the literature (Oliver, 1990), stability, reciprocity, and necessity have the greatest relevance.

\section{The arena of ASEAN tourism collaboration (Component 5)}

Component 5 is the arena of collaboration. It is the micro-environment in which the regime and its institutional arrangement exist. Power structure, political culture, cumulative experiences and learning, and commonality of interests, as discussed below, are factors in the arena that can influence achievement of ASEAN objectives for tourism development.

Young (1982) points out that regimes are never neutral with respect to their impact on the 
interests of participating actors, and powerful actors will exert whatever pressure they can in the effort to "devise constitutional contracts or legislative bargains favoring their interests" (P. 109). Therefore, shifts in the distribution of power will be reflected in changes in regimes.

Political culture is a set of general customs, values and beliefs shared by the actors. It is shaped by power relationships among actors, cumulative experiences of cooperation, and actors' behaviors in general. Klinjn et al. (1995) and Compston (2009) echo the importance of actors' preferences, perceptions of problems and solutions, and the rules and norms in policy decision-making in a policy network. As Keohane (1989) suggests, institutions and actors' behaviors have an interactive relationship. Actors shape the institutional arrangements that are developed for cooperative purposes, and institutions themselves affect the behavioral patterns of their members. Hence, alterations in the structure of rules and mechanisms in a regime are often coupled with changes in political culture.

In terms of cumulative experiences and learning, institutions may evolve subject to historicity as well as learning among actors and from their counterparts. The cumulative experiences of interactions can bring about changes in the political culture of cooperation, belief systems, and hence, interests of actors. As a result, states' policy preferences and institutional arrangements may change (Dougherty and Pfaltzgraff, 1996). Haas and Haas (1995, p.299-300) define learning as a "political process whereby consensual knowledge structured information that is generally accepted as true and accurate by members of the relevant professional community - is applied by policy makers to change their policy projects". They assert that learning by an international body is a powerful agent that induces organizational changes and improvement in international governance. A similar view is shared by Axelrod and Keohane (1986) who suggest that actors' decision-making is influenced by the ways in which they think about their problem, how their own actions will affect others, and how they will be interpreted by others. Their knowledge and experience in dealing with policy projects and with each other, therefore, impact the institution.

The empirical data confirm the relevance of "commonality of interests", "cumulative experiences and learning", and "political culture", while "power structure" did not show a great influence, probably due to the relative stability in the political condition in the region. It is obvious that all member states have the common interests of strengthening the competitiveness of tourism in the region, and liberalizing flows of money and people from outside and within the region. They are the foundations of collaboration.

When it comes to "experiences and learning", the build-up of trust, confidence and predictability among the policy-makers over years of working together, as well as the 
technical support provided by dialogue partners and universities, have improved the effectiveness and capability of members in working together. For instance, the ASEAN Australia Development Cooperation Program funds consultancy projects with the aim to strengthen ASEAN cooperation in various sectors including tourism. With "political culture", the ASEAN consensus-seeking approach affects tourism collaboration in various ways. One example is the development of the cooperation agenda. Based on the all-equal, consensus-seeking principle, a project must potentially bring benefits to all members. However, this often creates conflict within ASEAN since countries have contrasting sizes of economy and stages of development. In the case of creating a single visa for tourists traveling around the region for example, the less-developed countries may lose a considerable source of income by not having to issue their own national visa to tourists.

\section{The ASEAN tourism collaborative process (Component 6 to 8)}

Component 6 is the collaborative process. Collaboration is a process undertaken by the regime to achieve common goals of stakeholders. There are five dimensions to the nature of an institutional arrangement: first, the nature of constitutional documents - degree of formality, nature of commitments, and form of the agreement; second, the decision-making procedures - e.g. voting style; third, the modality of cooperation - substantive policy targets and procedural rules; fourth, the nature of coordination - decision-making, monitoring, and enforcement (Nesadurai, 2001); and fifth, the resources, i.e. leadership, expertise and financial resources etc. Within an institution, states seek to resolve issues and around them, actor expectations converge (Dougherty and Pfaltzgraff, 1996).

Wong et al. (2010) found in the case of ASEAN tourism, the adoption of a pragmatic, necessity-driven approach to policy-making. Concrete collaboration was only triggered by environmental factors such as terrorism and its effects. There is a lack of industry-specific procedural rules as well as monitoring and enforcement mechanisms. Hence, the modality of cooperation and the nature of coordination have not been clearly defined. On the other hand, resources (e.g. rules for members' monetary contribution), the nature of constitutional documents (e.g. various framework agreements), and decision-making procedures (e.g. conflict resolution and voting) are mandated by general, non-industry specific ASEAN agreements.

Component 7 is the set of factors that facilitate the collaborative process. The literature suggests that the success of the collaborative process may be affected by three factors: the degree of stake involved, the competency of actors to carry out the agenda, and the willingness of actors to collaborate.

Regarding the degree of stake involved, Vangen and Huxham (2003, p.5-6) suggest that the 
aim of collaboration, under most circumstances, is "to deal more effectively with major issues that sit in the organizations' inter-organizational domain and that cannot be tackled by any organization acting alone". Depending on the extent of stake involved, the degree of commitment from stakeholders, and thus the chance of success of the collaboration, may vary (Freeman, 1984). For example, if a substantial investment or the reputation of the organization is at stake, the collaboration plan is likely to receive much more attention from the stakeholders.

The second factor relates to the competency of an organization to manage the process. Externally, organizations need to have expertise in handling interorganizational relationships. Internally, management skills such as deployment of resources and leadership are essential to execute the collaboration plan within an organization (Zollo et al., 2002). Good strategic planning and organization skills are required from the top management involved.

Third, the willingness to engage oneself in the process and to implement what is planned can be regarded as a relational factor. It is independent of the first two factors That is, collaboration between two parties with a weak or negative relationship may not progress as planned even if they are competent to do so and a high stake is involved. Polonsky et al. (2002) propose that stakeholder relationships depend on the amount of trust, past and current interactions, power relations, commitment and the common interests among stakeholders. Husted (1994), using a transaction costs and social networks perspective, offered similar conclusion but adds that the degree of cooperation would increase when there is more than one link between the parties involved (in ASEAN, countries collaborate in more than one economic sector), if they share similar values and when potential cooperation is expected in the future.

Wong et al. (2011) concluded that the degree of stake each party holds, competency of the stakeholders to carry out the agenda, and the willingness of them to do so are all applicable to ASEAN tourism. However, by using the proposed three-dimensional approach, where factors are categorized into stakeholders, resources, and process and mechanisms, the authors realized that the collaboration phenomenon is very complex and cannot be fully explained by existing theories. They uncovered how entities external to ASEAN, such as the Greater Mekong Subregion (GMS), dialogue partners, and potentially the private sector, can contribute by improving the competency of some stakeholders. It was also found that the pragmatic orientation adopted by ASEAN in policy implementation has played a facilitating role. For instance, member states with less resources to implement certain policies are often given a flexible timeline. An interviewee in this study commented:

“... the [flexible] approach is actually a relief for ASEAN member 
countries, especially for those who want to move forward. For those who are not ready, then okay you can join later because now we want to move up to this.” (ASEAN Secretariat representative)

Finally, the importance of studying the political environment in a stratified manner was highlighted as the dynamics on the different levels of government have different impacts on the collaborative process - facilitating on the national level, creating impediments on the sectoral and departmental levels. These findings indicate that the boundaries of existing theories require expansion if they are to provide sufficient understanding of the success and failure factors associated with ASEAN collaboration in tourism.

Lastly, Component 8 is the feedback mechanism of the collaborative process. There is possible feedback from the regime to the basic causal variables, i.e. the actors, interactions among actors, and the preconditions. Krasner (1982, p.361) proposes four possible feedback mechanisms of established regimes. In essence, a feedback mechanism takes place when principles, norms, rules, and decision-making procedures alter the egoistic interests and power configurations that led to their creation in the first place. The four mechanisms are that regimes may: alter actors' calculations of how to maximize their interests, alter interests themselves, become a source of power to which actors can appeal, and/or alter the power capabilities of different actors, including states.

The empirical data confirm the occurrence of these four feedback mechanisms suggested by Krasner. In terms of a regime altering actors' calculations of interest by changing incentives and opportunities, an example in ASEAN tourism is the progress of visa facilitation made by some less-developed members such as Laos. Despite the fact that visa fees form a stream of income for the country, it has made itself visa-free for citizens of eight (out of nine) ASEAN states. Such a policy decision can be attributed to its commitment to regional cooperation. In other words, the country's participation in ASEAN tourism collaboration can be seen an incentive to streamline its visa policy.

Second, a regime may change the interests that led to its creation in the first place by "increasing transaction flow, facilitating knowledge and understanding, and creating property rights" (Krasner, 1982, p.362). One example in ASEAN tourism is the initiative of joint marketing. While there is inevitable competition between destinations, and to some, region-wide marketing may not make much sense, the effort of ASEAN joint promotion is slowly progressing, with the first overseas ASEAN trade show having debuted in November 2006 at the China International Travel Mart.

A third feedback mechanism is the situation where actors with limited national capabilities 
use the regime as a source of power (Krasner, 1982). Although the underlying resources of the actors may not change, their degree of influence may be enhanced by the principles, norms, rules, and decision-making procedures of the regime. This situation is most evident in the chairmanship mechanism of ASEAN tourism task forces. Currently, chairmanship of a task force is on a volunteer or upon-request basis. Cambodia, for example, volunteered to chair the marketing task force in 2004. This certainly empowers the less-developed member states to assert a certain degree of influence with respect to regional marketing.

Finally, a regime may alter the underlying power capabilities of their members. By facilitating particular patterns of behavior, a regime can strengthen or weaken the resources of particular actors (Krasner, 1982, p.365). There is no apparent example in ASEAN where the resources of a member are weakened thanks to the consensus-seeking principle. It is obvious, however, that the less-developed members are strengthened. The chairmanship example given above is one illustration. Moreover, the various region-wide competitiveness enhancement strategies (e.g. human resources development) and the financial and technical assistance provided by ASEAN's dialogue partners favor the development of the less-developed member countries. They may not enjoy these advantages if not for ASEAN. Their capabilities are, thus, enhanced due to the regime.

\section{CONCLUSIONS}

This model displays the mechanism of intergovernmental collaboration in tourism among ASEAN nations. It emphasizes the environments in which collaboration takes place - the economic and political environment of the world and of the region, as well as the arena of collaboration. Collaboration does not exist in a vacuum. Tourism, in particular, is highly sensitive to changes in the external environment. The impacts of the 9/11 incident and 2002 Bali bombing are in fact the key trigger to the formulation and implementation of the ASEAN Tourism Agreement. The model also highlights the interactivity of various components: among actors, between the institutional arrangement and the actors, and the feedback mechanism between the collaborative process and the preconditions of collaboration. The interactivities reflect the dynamic nature of collaboration.

While the study found some degree of congruence between theories and the empirical findings, there are certain aspects of ASEAN tourism which existing theories do not appear to explain fully. The special dynamics that tourism brings into the collaboration are highlighted by several components in the model. For example, Component 3 , the "actors" in the collaboration can be specified as "state actor - nation state; economic ministries; tourism ministries". The multilayered structure is a result of the relatively weak political power tourism has as a sector, and the need for national level support. The "preconditions" in Component 4 - necessity (direct precondition), reciprocity, and stability (indirect 
preconditions) - are found to be the most relevant to ASEAN tourism. The formation of ASEAN tourism collaboration was directly driven by necessity in order to support a wider economic agenda. Because of the competitive nature of tourism, seeking mutual benefits (reciprocity) was not the immediate motive. By extending the contextual boundaries of existing theories with new empirical evidence, this research makes theoretical contribution to the study of intergovernmental collaboration.

The model proposed in this paper provides a coherent picture of ASEAN tourism, a collaboration that has both economic and political significance. Given a strong theoretical basis on which it was built as well as the empirical data it integrated, this model assists in the understanding of the ASEAN tourism phenomenon. However, as ASEAN members evolve in their political, social and economic development alongside variations in the global economic environment and dramatic events, so too will the nature of their tourism collaboration. On-going research is required to observe and analyze the dynamic phenomena. This will not only help advance theories but also contribute to the success of the collaboration, and in turn, the development of the member countries. Further studies can also be conducted to examine the applicability of the ASEAN model in other regions, such as Latin America and the Caribbean where supranational collaboration in tourism also exists. Mutual learning opportunities may be identified as a result. 
Table 1: Contribution of travel and tourism to ASEAN members' GDP

\begin{tabular}{|c|c|c|}
\hline Country & $\begin{array}{l}\text { GDP per capita (2008 estimates) } \\
\text { (USD, in current prices) }^{1}\end{array}$ & $\begin{array}{l}\text { Contribution of travel and tourism } \\
\text { to GDP (2009 estimates) }(\%)^{2}\end{array}$ \\
\hline Brunei & 35622 & 11.5 \\
\hline Cambodia & 756 & 17.5 \\
\hline Indonesia & 2236 & 7.8 \\
\hline Laos & 917 & 10.8 \\
\hline Malaysia & 7991 & 12.3 \\
\hline Myanmar & 464 & 6.5 \\
\hline Philippines & 1843 & 8.7 \\
\hline Singapore & 38046 & 7.3 \\
\hline Thailand & 4116 & 14.7 \\
\hline Vietnam & 1052 & 13.1 \\
\hline ASEAN & 2581 & 11.0 \\
\hline
\end{tabular}

${ }^{1}$ Source: ASEAN (2009b). Selected basic ASEAN indicators. Retrieved August 15, 2009 from http://www.aseansec.org.

${ }^{2}$ Source: WTTC (2009). The 2009 Travel \& Tourism Economic Research. Retrieved August 15, 2009 from http://www.wttc.org. 
Fig. 1: ASEAN Tourism Collaboration Model

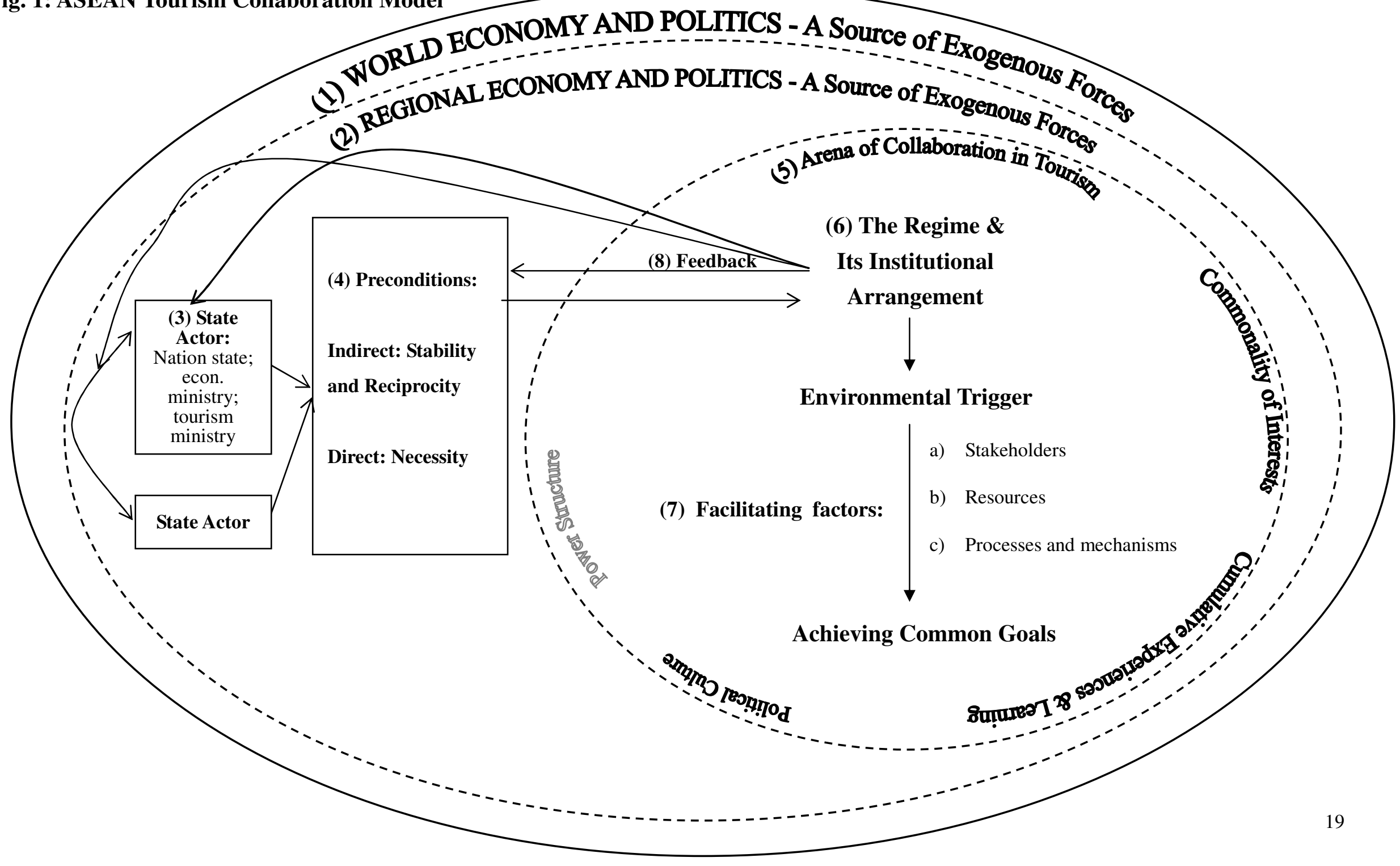




\section{References}

Acharya, A. (2000). Constructing a Security Community in Southeast Asia. New York, Routledge.

ASEAN (2002). ASEAN Tourism Agreement. Jakarta: ASEAN Secretariat.

ASEAN (2006). Joint Media Statement of the Thirty-Eight ASEAN Economic Ministers' (AEM) Meeting. 22 August 2006. ASEAN Press Release. Jakarta: ASEAN Secretariat.

ASEAN (2009a). Tourist arrivals in ASEAN. Retrieved August 15, 2009 from http://www.aseansec.org.

ASEAN (2009b). Selected basic ASEAN indicators. Retrieved August 15, 2009 from http://www.aseansec.org.

Axelrod, R., \& Keohane, R.O. (1986). Achieving cooperation under anarchy: strategies and institutuions. In K. A. Oye (Ed). Cooperation under Anarchy (pp. 226-254). New Jersey: Princeton University Press.

Cetron, M. (2001). The world of today and tomorrow: the global view. In A. Lockwood \& S. Medlik (Eds). Tourism and Hospitality in the $21^{\text {st }}$ Century. Oxford: Butterworth-Heinemann.

Compston, H. (2009). Policy Networks and Policy Change: Putting Policy Network Theory to the Test. New York: Palgrave Macmillan.

Dougherty, J. E., \& Pfaltzgraff, R.L. Jr. (1996). Contending Theories of International Relations: A Comprehensive Survey. New York: Addison-Wesley Education Publishers Inc.

Drysdale, P. (1988). International Economic Pluralism: Economic Policy in East Asia and the Pacific. Sydney: Allen \& Unwin Pty Ltd.

Dwyer, L., \& Edwards, D. (2009). Managing tourism to avoid 'strategic drift'. International Journal of Tourism Research, 11(4), 321-335. 
Dwyer, L., Edwards, D., Mistilis, N., Scott, N., \& Roman, C. (2009). Destination and Enterprise Management for a tourism future. Tourism Management, 30, 63-74.

Evans, N., Campbell, D., \& Stonehouse, G. (2003). Strategic Management for Travel and Tourism. Oxford: Butterworth-Heinneman.

Fahey, L., \& Narayanan, V.K. (1986). Macroenvironmental Analysis for Strategic Management. St. Paul, MN: West Publishing Company.

Freeman, R. E. (1984). Strategic Management: A Stakeholder Approach. Marshfield: Pitman.

Gibbs, G.R. (2002). Qualitative Data Analysis: Explorations with NVivo. Buckingham: Open University Press.

Goldblatt, D., Perraton, J., Held, D., McGrew, A., \& Anthony, A. (2006). Global Transformations: Politics, Economics and Culture. Cambridge: Polity Press.

Hall, C. M. (2005). Tourism: Rethinking the Social Science of Mobility. Harlow: Prentice Hall.

Hammond, A. (1998). Which World? Scenarios for the 21 ${ }^{\text {st }}$ Century: Global Destinies, Regional Choice. New York: Island Press.

Haas, P. M., \& Haas, E.B. (1995). Learning to learn: some thoughts on improving international governance of the global problematique. Issues in Global Governance Papers written for the Commission on Global Governance (pp. 295-332). London: Kluwer Law International.

Husted, B. W. (1994). Transaction costs, norms, and social networks. Business and Society, 33(1), 30-57.

Keohane, R. O. (1989). International Institutions and State Power. Boulder: Westview Press.

Klijn, E., Koppenjan, J., Termeer, K. (1995). Managing networks in the public sector: a theoretical study of management strategies in policy networks. Public 
Administration 73: 437-454.

Krasner, S. D. (1982). Regimes and the limits of realism: regimes as autonomous variables. In S. D. Krasner (Ed). International Regimes (pp. 355-368). Ithaca: Cornell University Press.

Lincoln, Y. S., \& Guba, E.G. (1985). Naturalistic Inquiry. Beverly Hills: Sage Publications Inc.

National Intelligence Council (NIC) (2004). Mapping the Global Future. Washington: National Intelligence Council.

Nordin, S. (2005). Tourism of Tomorrow - Travel Trends \& Forces of Change. ETOUR, European Tourism Research Institute.

Oliver, C. (1990). Determinants of Interorganizational relationships: integration and future directions. Academy of Management Review, 15(2), 241-265.

Peters, B. G., \& Pierre, J. (2001). Developments in intergovernmental relations: towards multi-level governance. Policy \& Politics, 29(2), 131-135.

Polonsky, M. J., Schuppisser, D.S.W., \& Beldona, S. (2002). A stakeholder perspective for analyzing marketing relationships. Journal of Market - Focused Management, 5(2), 109.

Tan, G. (2003). ASEAN Economic Development and Cooperation (3rd ed.). Singapore: Times Academic Press.

Timothy, D. J. (2003). Supranationalist alliances and tourism: insights from ASEAN and SAARC. Current Issues in Tourism, 6(3), 250-266.

UN-World Tourism Organization (2000). Tourism 2020 Vision - Volume 3 East Asia and the Pacific. Madrid: World Tourism Organization.

UN-World Tourism Organization (2003). UNWTO World Tourism Barometer (January 2003). Madrid: World Tourism Organization.

Vangen, S., \& Huxham, C. (2003). Nurturing collaborative relations: building trust in 
interorganizational collaboration. The Journal of Applied Behavioral Science, 39(1), $5-31$.

Wong, E.P.Y., Mistilis, N., \& Dwyer, L. (2010). Understanding ASEAN tourism collaboration - Preconditions and policy framework formulation. International Journal of Tourism Research, 12(3), 291-302.

Wong, E.P.Y., Mistilis, N., \& Dwyer, L. (2011). A framework for analyzing intergovernmental collaboration - The case of ASEAN Tourism. Tourism Management, 32, 367-376.

WTTC (2009). The 2009 Travel \& Tourism Economic Research. Retrieved August 15, 2009 from http://www.wttc.org.

Yeh, R. S. (2002). Association of South-East Asian Nations. International Encyclopedia of Business and Management. In M. Warner (Ed). London: Thomson Learning. 1, 296-299.

Yin, R. K. (2003). Case Study Research: Design and Methods (3rd ed.). Thousand Oaks: Sage Publications.

Young, O. R. (1982). Regime dynamics: the rise and fall of international regimes. In S. D. Krasner (ed). International Regimes (pp. 93-113). Ithaca: Cornell University Press.

Zollo, M., Reuer, J.J. and Singh, H. (2002). Interorganizational routines and performance in strategic alliances. Organization Science, 13(6), 701-713. 